\title{
Intelligence and psychosocial adjustment in velocardiofacial syndrome: a study of 37 children and adolescents with VCFS
}

\author{
A Swillen, K Devriendt, E Legius, B Eyskens, M Dumoulin, M Gewillig, J P Fryns
}

\begin{abstract}
We report data on a group of 37 VCFS patients with specific reference to their intelligence, behaviour, and social competence. Fifty five percent of the children had a borderline to normal IQ. Mental retardation (defined as IQ $<70$ or $>-2$ SD below the mean) was found in $45 \%$. In the majority, the mental retardation was mild (38\%) and only two patients had moderate mental retardation. Severe mental retardation seems to be rare in VCFS. The present study shows also that the incidence of mental retardation is much higher in the familial than the de novo group. Intelligence is not correlated with the presence or absence of a heart defect. Significantly higher verbal IQs than performance IQs (probably related to deficits in visuospatial-perceptual functioning) were found. Problems in social-emotional functioning and attention were also found. Further longitudinal studies are necessary to provide an accurate prognosis and appropriate intervention for VCFS children.

(F Med Genet 1997;34:453-458)
\end{abstract}

Keywords: velocardiofacial syndrome; intelligence; behaviour; social competence

The velocardiofacial syndrome (VCFS) was initially described by Shprintzen et $a^{1}$ in 1978 as a multiple congenital malformation syndrome. Its major features are a cleft palate or velopharyngeal insufficiency, cardiac anomalies, typical facial appearance, learning disabilities, or mental retardation. The discovery of a submicroscopic deletion in chromosome $22 \mathrm{q} 1^{2}$ in the majority of patients has confirmed that VCFS is a specific syndrome. In most patients the deletion occurs de novo, but autosomal dominant inheritance with variable expression has been observed. Both severely and mildly phenotypically affected patients with the 22q11 deletion have been observed. ${ }^{3}$ So far, no predictive factors for the severity of the disorder have been identified.

Although learning disabilities or mental retardation have almost invariably been found in VCFS, only one study in patients assessed at a craniofacial centre has so far specifically tested the cognitive abilities and language profiles of these children. ${ }^{4}$
We report data on a group of 37 VCFS patients with specific reference to their intelligence, behaviour, and social competence.

\section{Material and methods}

PATIENTS

We studied a group of 37 consecutively diagnosed children and adolescents with VCFS. Eleven were identified in a prospective study of patients with a conotruncal heart defect. ${ }^{5}$ The main presenting symptoms of the remaining 26 patients were as follows: congenital heart defect in six, developmental delay in eight, behavioural problems in three, and velopharyngeal insufficiency in three. The remaining six patients were affected sibs of index patients.

Table 1 gives a summary of the age at time of diagnosis, origin of the deletion (familial or de novo), presenting symptoms, mental level/IQ of the patients, and educational level of the parents.

The study group consisted of 19 males and 18 females $(n=37)$. Their age, at the time of the testing, varied from 8 months to 20 years. All patients presented features of the VCFS and all had a 22q11 deletion (shown by fluorescence in situ hybridisation using probe DO832). ${ }^{6}$ In 25 of these 37 patients, the $22 \mathrm{q} 11$ deletion was of de novo origin and in 12 of familial origin (nine maternal, three paternal).

Two thirds of the children and adolescents ( 24 or $65 \%$ ) had a heart defect. Three children had a cleft palate which was surgically repaired and nine children had a pharyngoplasty for velopharyngeal insufficiency.

\section{PSYCHOMETRIC TESTS}

We completed a psychometric evaluation in all 37 subjects aged between 8 months and 20 years. Medical and psychosocial history were obtained from medical records and parental interview. Data on intelligence were obtained by formal IQ tests, and a behaviour rating scale was completed by the parents. All children were tested by the same person (AS) at home.

\section{Intelligence}

The following intelligence tests were used according to age: the youngest children (8-30 months) were evaluated with the Bayley Developmental Scales $(\text { BOS 2-30) })^{7}(\mathrm{n}=11)$. The McCarthy Developmental Scales ${ }^{8} 9$ were used in two children (aged 2 years 6 months and 3 years 11 months, respectively) and the Snijders-Oomen Non-Verbal Intelligence Test- 
Table 1 Description of the study group

\begin{tabular}{|c|c|c|c|c|c|c|c|}
\hline No & Sex & Age & Fam & $\begin{array}{l}\text { Presenting } \\
\text { symptoms }\end{array}$ & Mental level/IQ & $E d u c M^{*}$ & $E d u c F^{\star}$ \\
\hline 1 & $M$ & $0 ; 3$ & $\mathrm{~N}$ & Cardio screen & Normal & 4 & 3 \\
\hline 2 & $\mathrm{~F}$ & $0 ; 4$ & $\mathbf{N}$ & Cardio screen & Delayed & 3 & 4 \\
\hline 3 & $\mathrm{~F}$ & $1 ; 6$ & $\mathrm{~N}$ & Cardio + dev delay & Moderate MR & 5 & 5 \\
\hline 4 & $\mathrm{~F}$ & $2 ; 0$ & $\mathrm{Y}$ & Dev delay & Mild MR & 1 & 2 \\
\hline 5 & $F$ & $2 ; 0$ & $\mathrm{~N}$ & Dev delay+FD & Borderline (86) & 3 & 3 \\
\hline 6 & $\mathbf{M}$ & $0 ; 5$ & $\mathrm{~N}$ & Heart defect & Borderline & 5 & 5 \\
\hline 7 & $M$ & $2 ; 10$ & $\mathrm{~N}$ & Dev delay & Normal(100) & 5 & 3 \\
\hline 8 & $\mathrm{M}$ & $3 ; 3$ & $\mathrm{~N}$ & Cardio screen & Borderline (85) & 3 & 3 \\
\hline 9 & $\mathbf{M}$ & $0 ; 1$ & $\mathrm{Y}$ & Familial & Mild MR & 3 & 2 \\
\hline 10 & $M$ & $2 ; 0$ & $\mathrm{~N}$ & Heart defect & Normal (92) & 4 & 4 \\
\hline 11 & M & $3 ; 11$ & $\mathrm{~N}$ & Heart defect & Borderline (79) & 1 & 2 \\
\hline 12 & $\mathrm{~F}$ & $3 ; 6$ & $\mathrm{~N}$ & VPI & Borderline (80) & 3 & 3 \\
\hline 13 & $\mathrm{~F}$ & $4 ; 7$ & $\mathrm{~N}$ & Dev delay & Normal (90) & 5 & 5 \\
\hline 14 & $\mathrm{~F}$ & $5 ; 0$ & $\mathbf{N}$ & VPI & Normal (94) & 3 & 4 \\
\hline 15 & $\mathrm{M}$ & $5 ; 8$ & $\mathrm{~N}$ & Cardio screen & Borderline (76) & 5 & 5 \\
\hline 16 & $\mathrm{~F}$ & $5 ; 3$ & $\mathrm{Y}$ & Familial & Mild MR (59) & 1 & 1 \\
\hline 17 & $\mathrm{~F}$ & $5 ; 0$ & $\mathrm{Y}$ & Dev delay & Mild MR (61) & 1 & 2 \\
\hline 18 & M & $6 ; 0$ & $\mathrm{~N}$ & Cardio screen & Mild MR (65) & 3 & 5 \\
\hline 19 & $\mathbf{F}$ & $3 ; 0$ & $\mathrm{~N}$ & Dev delay+FD & Normal (100) & 4 & 4 \\
\hline 20 & $\mathbf{M}$ & $6 ; 6$ & $\mathrm{~N}$ & Behavioural probl & Mild MR (69) & 3 & 3 \\
\hline 21 & $\mathrm{~F}$ & $5 ; 0$ & $\mathrm{Y}$ & VPI+short stature & Mild MR (60) & 1 & 2 \\
\hline 22 & $M$ & $6 ; 4$ & $\mathrm{Y}$ & Dev delay & Moderate $(<50)$ & 2 & 3 \\
\hline 23 & $\mathrm{M}$ & $8 ; 5$ & $\mathrm{Y}$ & Familial & Severe MR (24) & 1 & 1 \\
\hline 24 & $\mathrm{M}$ & $9 ; 6$ & $\mathbf{N}$ & Cardio screen & Borderline (75) & 5 & 5 \\
\hline 25 & $\mathrm{~F}$ & $10 ; 7$ & $\mathrm{~N}$ & Cardio screen & Borderline (82) & 5 & 5 \\
\hline 26 & M & $9 ; 0$ & $\mathrm{~N}$ & Cardio screen & Normal (87) & 3 & 4 \\
\hline 27 & $\mathrm{M}$ & $9 ; 3$ & $\mathrm{Y}$ & Familial & Mild MR (59) & 2 & 3 \\
\hline 28 & $\mathrm{~F}$ & $8 ; 0$ & $\mathrm{Y}$ & Familial & Mild MR (60) & 2 & 1 \\
\hline 29 & $\mathrm{~F}$ & $7 ; 0$ & $\mathrm{~N}$ & Behavioural probl & Borderline (80) & 5 & 5 \\
\hline 30 & $\mathrm{~F}$ & $10 ; 0$ & $\mathrm{~N}$ & Heart defect & Normal (86) & 5 & 5 \\
\hline 31 & $\mathrm{M}$ & $9 ; 0$ & $\mathrm{Y}$ & Cardio screen & Mild (57) & 2 & 1 \\
\hline 32 & $M$ & $12 ; 0$ & $\mathbf{N}$ & Behavioural probl & Mild (69) & 2 & 2 \\
\hline 33 & $\mathrm{~F}$ & $16 ; 5$ & $\mathrm{~N}$ & Cardio screen & Mild (55) & 3 & 3 \\
\hline 34 & $\mathrm{~F}$ & $16 ; 0$ & $\mathrm{Y}$ & Cardio screen & Borderline (77) & 2 & 5 \\
\hline 35 & $\mathrm{M}$ & $17 ; 0$ & $\mathbf{N}$ & $\begin{array}{l}\text { Heart defect + } \\
\text { short stature }\end{array}$ & Borderline (73) & & \\
\hline 36 & $M$ & $16 ; 0$ & $\mathrm{~N}$ & Dev delay & Mild MR (65) & 4 & 5 \\
\hline 37 & $\mathrm{~F}$ & $20 ; 8$ & $\mathrm{Y}$ & Familial & Normal (86) & 2 & 5 \\
\hline
\end{tabular}

Age $=$ age at time of diagnosis, Fam=familial occurrence of the del(22q11), Y=Yes, N=No, Dev delay=developmental delay, Cardio screen=patients ascertained through systematic screening of patients with conotruncal heart disease, VPI=velopharyngeal insufficiency, Mental level/ $\mathrm{IQ}=$ mental level/IQ of the patient, EducM=educational level of the mother, $\mathrm{EducF}=$ educational level of the father.

$\dagger 1=$ primary school or special school, $2=$ vocational training, $3=$ secondary technical school, $4=$ secondary general school, $5=$ college/university.

Revised (SON-R $)^{10}$ in two other children with gross delay in verbal development. The Wechsler Primary Preschool Scale of Intelligence (WPSSI) ${ }^{11}$ was used in nine preschool children (age range 4-6 years 5 months, mean age 6 years), the Wechsler Intelligence Scale for Children-Revised (WISC-R) ${ }^{12}$ was used in 11 school age children and young adolescents (age range $7-16$ years, mean age 12 years 4 months), and the Wechsler Adult Intelligence Scale (WAIS) ${ }^{13}$ in a 20 year old adolescent girl. The Terman-Merrill intelligence scale ${ }^{14}$ was used in one mentally retarded boy. Dutch norms were used, except for the Terman-Merrill intelligence scale.

\section{Behaviour and social competence}

The Dutch version of the Child Behaviour Checklist (CBCL) ${ }^{15}$ was used to obtain standardised reports of problem behaviour in children and adolescents. Parents of 25 patients completed the CBCL 2-3 years $(n=6)$ or the CBCL 4-18 years $(n=19)$, according to the corresponding age of their child. In nine children, CBCL data could not be collected because the children were too young $(<2$ years of age). In the remaining three children, CBCL data were incomplete, so that $\mathrm{T}$ scores could not be calculated. The CBCL consists of 112 behaviours (problem items), and these are scored as follows: 0 if the item is "not true" for
Table 2 Milestones in motor development in VCFS

\begin{tabular}{llll}
\hline & \multicolumn{3}{c}{$I Q>70$} \\
\cline { 3 - 4 } Milestones in motor development & Mean & SEM \\
\hline Sitting alone & $8.1 \dagger$ & 9.6 & 1.064 \\
Crawling & 8.7 & $12.0^{\star}$ & 1.633 \\
Standing alone & 13.4 & 13.6 & 1.208 \\
Walking alone & 14.1 & $18.8^{\star \star}$ & 1.447
\end{tabular}

$\star$ Significant $\mathrm{p}<0.05 .{ }^{\star} \star$ Significant $\mathrm{p}<0.01$

†Mean (according to Bayley Developmental Scales (2-30 months). ${ }^{7}$

the child, 1 if the item is "somewhat or sometimes true", and 2 if it is "very true or often true". A total problem score is computed by summing all $0 \mathrm{~s}, 1 \mathrm{~s}$, and $2 \mathrm{~s}$. We used the cross informant syndrome constructs as reported by Achenbach. ${ }^{16}$ The results from the checklist are transformed first into a total problem score, second into two subscores for respectively internalising (withdrawn, somatic complaints, and anxious/depressed) and externalising problem behaviour (delinquent and aggressive), and third into a profile of clusters with specific problem behaviour (withdrawn, somatic complaints, anxious/depressed, social problems, thought problems, attention problems, delinquent behaviour, and aggressive behaviour).

$T$ scores $(X=50, S D=10)$ were calculated for each patient. For the total problem score, and the internalising and externalising subscores, a total $\mathrm{T}$ score of 63 or higher (90th centile or higher) is considered to be in the "clinical" range. $T$ scores (for the separate syndromes) in the range of 70 or higher ( $>98$ th centile) are found in populations with severe behavioural or emotional problems. For the specific problem clusters, a T score of 66 or higher ( $>93 \mathrm{rd}$ centile) are considered to be of concern. ${ }^{14}$

We also interviewed the parents and reviewed medical records and child welfare data concerning the early development of the child (motor and language milestones) and the school performance, and the socioeconomic status (SES) of the parents (for example, educational level, current occupation).

\section{STATISTICAL ANALYSIS}

Analysis of covariance, $t$ tests, sign test, and Scheffés post hoc test were performed where indicated.

\section{Results}

DEVELOPMENTAL HISTORY

In 13 children, the parents could not give accurate and complete information on developmental milestones. Developmental data were obtained on 24 children. The majority of children had delayed motor and language development. With regard to motor development, even the children with a normal to borderline intelligence (IQ >70) were statistically significantly slower (compared with normally developing peers) in reaching the milestones "crawling" and "walking alone" (table 2).

Data on language development (first words, first sentences) could not be statistically tested, owing to missing data. The children with nor- 
mal and borderline IQ (IQ >70) spoke their first words around 18 months (mean age) and first sentences around 36 months (mean age). The mentally retarded children spoke their first words at 32 months (mean age) and their first sentences at 60 months (mean age, 5 years).

INTELLIGENCE AND SCHOOL PERFORMANCE

Intelligence and cognitive profile

Twenty children (55\%) had normal (IQ >86) $(n=9)$ or borderline (IQ 71-85) $(n=11)$ intelligence. In 18 of these 20 children $(90 \%)$ the $22 \mathrm{q} 11$ deletion was of de novo origin and in $2 / 20(10 \%)$ the deletion was familial (inherited from their mother) (table 1). Seventeen children $(45 \%)$ were mentally retarded (IQ $<70)$. Fourteen of them had mild mental retardation ( $I Q=55-69)$, two were moderately mentally retarded (IQ <50), and one child was severely mentally retarded $(I Q=24)$. The mean IQ of the children in whom the presenting symptom was developmental delay $(n=8$; familial deletion in three, de novo deletion in five) was 71.85 , which is not significantly different from the mean IQ of 69.05 of the remaining patients $(n=29$; familial deletion in nine, de novo deletion in 20).

In the group of mentally retarded children and adolescents, the incidence of familial deletions (three paternal transmission, nine maternal transmission) was high (12/17 or $70.5 \%)$. Of the 25 patients with a de novo $22 \mathrm{q} 11$ deletion, only seven ( $28 \%$ ) were mentally retarded, compared with 10 of the 12 patients $(83.3 \%)$ with a familial transmission of the deletion. The incidence of mental retardation is thus higher in familial than in de novo cases: mean FSIQ of familial cases $(n=9)$ was 63.2 (SD 11.08) (fig 1) which is statistically significantly lower than the mean FSIQ of de novo cases $(n=20)$ with an IQ of 79.8 (SD 11.8) ( $\mathrm{p}<0.002$, Student's $t$ test). In this analysis, one patient with a familial deletion and severe mental retardation was excluded. A possible relationship of IQ with parental educational level was studied by covariance analysis. When we corrected for the educational level of the mother and father in a covariance analysis, the mean FSIQ of familial cases was not statistically significantly lower than the mean FSIQ of the de novo cases. However, when we corrected only for educational level of the father, the mean FSIQ of the familial cases was still significantly lower than the mean FSIQ of the de novo cases.

The mean FSIQ of the children with a heart defect $(n=17)$ was 77.2 , and for the children without a heart defect mean FSIQ was 67.3, which is not statistically significant (Student's $t$ test, $\mathrm{p}=0.10447$ ).

Looking at the VIQ-PIQ differences, we found for the total group (tested with Wechsler scales) $(n=20)$ a statistically significant difference between the average verbal IQ of 78 (SD 14.7) and average performance IQ of 70 (SD 11.3) (paired Student's $t$ test, p<0.001). In the group of nine young children (mean age 6 years, WPPSI results), we found a mean verbal IQ of 75.5 and a performance IQ of 70.2 (not significant). In the group of the 11 older

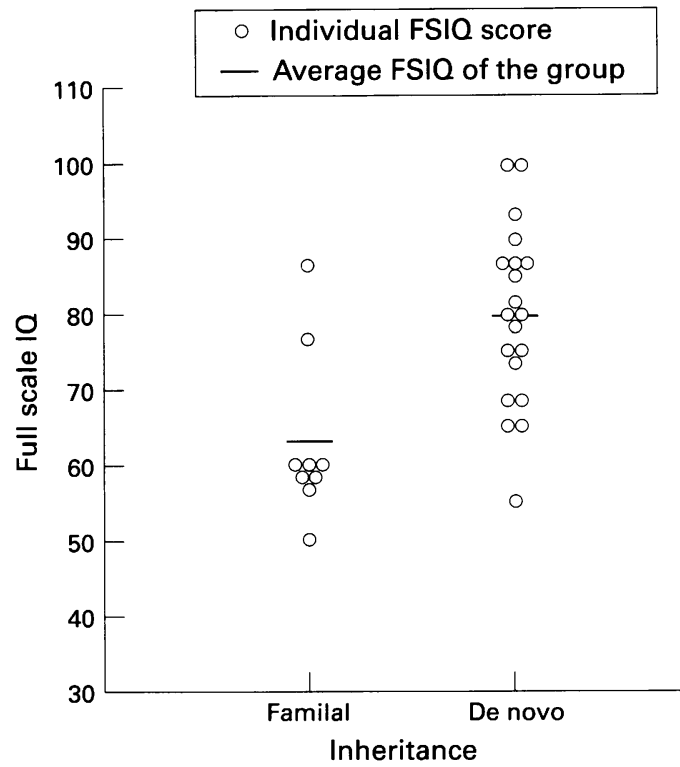

Figure 1 Intelligence of VCFS patients with a familial deletion $22 q 11$ versus a de novo $22 q 11$ deletion.

children (mean age 12 years; WISC-R results) we found a mean verbal IQ of 79 and a mean performance IQ of $69(p<0.001)$.

\section{Educational level and school performance}

Parents. The educational level of the parents of familial cases was significantly lower than nonfamilial cases $(p=0.00007$, Kruskal-Wallis one way ANOVA).

Children and adolescents. Of the total group of 37 children and adolescents, 30 children attend school. Thirteen (age range 3-16 years) attend regular classes: seven are now in preschool (one child has repeated one class), three are in primary school (two of them have repeated one class), and three are in secondary school (two have repeated one class). All children receive speech therapy with special attention to articulation, grammar, and syntax. Remedial teaching, especially for mathematics, is required for most of the children.

The remaining 17 children (age range 5-16 years) attend special classes. Three children are in a special school for normal intelligent children with severe learning disabilities. The remaining 14 attend schools for the mildly to moderately mentally retarded. All receive an intensive programme for early reading, writing, and arithmetic, speech therapy, psychomotor therapy, and training in social skills and self-care.

\section{BEHAVIOUR}

In the toddler group (children between 2 and 3 years, $n=6$ ), somatic complaints ("constipation" and "eats poorly") and (social) withdrawal were reported in five of the six children on the CBCL. Only one child had a total T score within the clinical range $(T>63)$.

For the older children and adolescents $(n=19)$, the mean T scores on the CBCL 4-18 years for the total group on total problem score, on internalising, externalising, and on the different clusters of problem behaviour are given in table 3. Highest scores were found on "Social problems" (average $\mathrm{T}$ score of 64), 
Table 3 Average T scores on the CBCL 4-18 for the total group $(n=19)$

\begin{tabular}{lll}
\hline & $T$ scores & SEM \\
\hline Total problem score & 52.2 & 2.206 \\
Total internalising score & 54.5 & 2.206 \\
Total externalising score & 49.9 & 2.206 \\
Withdrawn & 58.6 & 1.603 \\
Somatic complaints & 54.9 & 1.603 \\
Anxious & 54.3 & 1.603 \\
Social problems & 64.7 & 1.603 \\
Thought problems & 55.8 & 1.603 \\
Attention problems & 64.1 & 1.603 \\
Delinquent behaviour & 52.5 & 1.603 \\
Aggressive behaviour & 54.6 & 1.603 \\
\hline
\end{tabular}

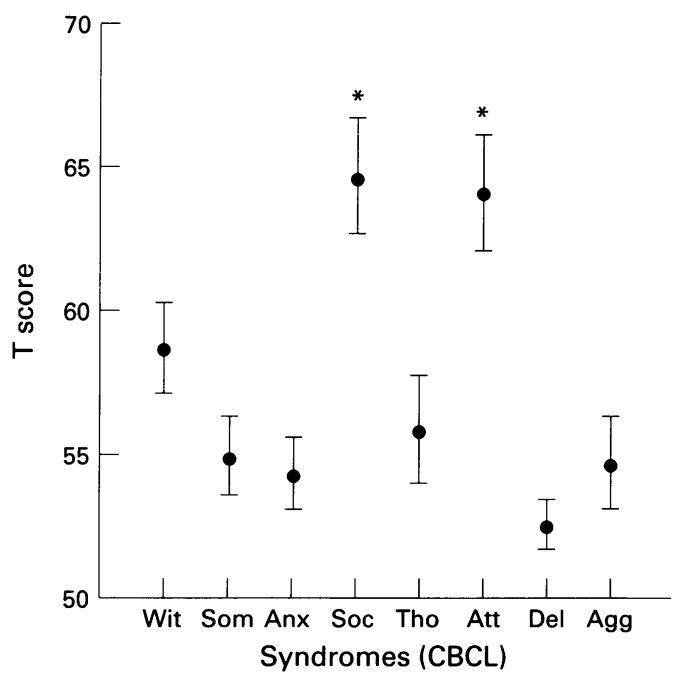

Figure 2 Behavioural profile in VCFS (CBCL 4-18). X axis: Wit $=$ withdrawn, Som=somatic complaints, Anx=anxious, Soc =social problems, Tho=thought problems Att $=$ attention problems, Del=delinquent behaviour, Agg=aggressive behaviour. $Y$ axis: average $T$ scores for the total group for the different syndromes. * Statistically significant higher score (Scheffé's test post hoc).

"Attention problems" (average T score of 64), and "Withdrawn" (average T score of 58). Post hoc statistical test (Scheffe's test) shows that the clusters "Social problems" and "Attention problems" score statistically significantly higher than the other clusters of problem behaviour, except the cluster "Withdrawn" (fig 2)

For the interpretation of the results, a distinction was made between the normal/borderline intelligent children (IQ $>70, n=12$ ) and the group of children with mental retardation (IQ <70, $\mathrm{n}=7$ ). This distinction was made because there are no norms available for the mentally retarded children.

In the group of normal/borderline intelligent children, three out of 12 (patients 13, 28, and 35) had a total $\mathrm{T}$ score within the clinical range $(T>63)$. In individual patients, "clinical" scores on the syndromes ( $\mathrm{T}$ score $>70$ ) were found for "Attention problems" $(n=3)$, "Social problems" ( $n=3)$, "Thought problems" $(n=1)$, and "Withdrawn" $(n=1)$. The same behavioural profile with "peaks" at "Attention problems", "Social problems", and "Withdrawn" was also found in the non-clinical group ( $T$ $<70$ ) but was less pronounced. This profile was already found at the age of 5 years and we found no differences between boys and girls. We also found evidence for higher scores (but non-clinical) on anxiety/depression for the older children (11 years and older) with VCFS.

In the group of mentally retarded children $(n=7)$, two out of seven (patients 16 and 18) had a total $\mathrm{T}$ score within the clinical range. Clinical scores on the syndromes $(T>70)$ were found on "Social problems" $(n=5)$ and on "Attention problems" $(\mathrm{n}=3)$.

\section{Discussion}

In the present study of 37 patients with VCFS and a deletion in $22 \mathrm{q} 11$, we confirm that one of the main clinical features of this syndrome is learning disability or mental retardation. Mental retardation (defined as FSIQ $<70$ or $>-2$ SD below the mean) was found in $45 \%$. In the majority of them, the mental retardation was mild (38\%) and only two patients had moderate mental retardation. Severe mental retardation seems to be rare in VCFS. Only one child with a familial deletion and cerebellar hypoplasia (patient 23) was severely retarded. In their initial description of the syndrome Shprintzen et $a l^{1}$ recognised the presence of learning disabilities in all patients. Since then, learning difficulties have been reported in $82 \%^{17}$ to $100 \%{ }^{18}$ of the patients with VCFS. Mental retardation (not specifically defined) seems to be present in $40 \%{ }^{19}$ to $46 \% .{ }^{18}$ In the present study, eight patients were initially referred for diagnosis because of developmental delay. This could have introduced a bias in the study. However, we found no difference in FSIQ between this group of patients and the remaining patients. Our findings are therefore representative of VCFS, irrespective of their referral pattern. Also, in this series, 37 consecutively diagnosed patients were examined, thus eliminating a further possible bias.

The present study also confirms a wide variability in intelligence in VCFS patients. Until now there have been no good explanations for this variability in intelligence (for example, no correlation with the extent of the deletion). Also, we found no correlation between intelligence and the presence or absence of a congenital heart defect. However, the incidence of mental retardation was found to be much higher in the patients with a familial deletion than in patients with a de novo deletion. We found a statistically significant difference of 16.6 IQ points between the mean FSIQ of the patients with a "familial" deletion (mean FSIQ 63.2) and the mean FSIQ of the patients with a "de novo" deletion (mean FSIQ 79.8). As far as we know, this has not been reported in VCFS. This difference, however, can possibly be explained in part by the lower educational level of the affected parents than the unaffected parents. Indeed, parental IQ and socioeconomic status are major determining factors of the IQ in their children, and this was estimated here by their educational level. This is further supported by the two patients with a familial deletion but a FSIQ of respectively 77 (patient 34) and 86 (patient 37): their unaffected parent had a higher educational level compared to parents of other familial cases (table 1). Except for these two patients, the parent in familial cases, not 
carrying the deletion, had a lower SES compared to parents of de novo cases, suggesting assortative mating. Associated cerebral malformations could also be a possible explanation: in the present study, the severely mentally retarded boy (patient 23) showed a cerebral malformation, although Mitnick et $a l^{20}$ did not find such a correlation.

More studies are needed to confirm these results and to determine the impact on intelligence of other associated malformations or factors, such as hypoparathyroidism, parental origin of the deletion, or immune status.

Besides the distribution of intelligence, the present study also provided data on the intelligence profile of these children. Analysis of the Wechsler subscales showed a statistically significant difference between the average verbal IQ and average performance IQ.

Subtest analysis was not done because of the small number of children tested by the WISC-R $(n=11)$. In most children, however, specific cognitive deficits (that is, visuoperceptual-spatial ability and planning ability) could be suspected from the profile of the WISC-R. These results indicate that children with VCFS possibly might have a higher risk for developing problems in the field of visuoperceptual-spatial abilities and of executive functioning. This needs further investigation in a larger patient group, however. We prefer to refer to learning disabilities only in the group of children who are not mentally retarded (FSIQ >70). The term "learning disabilities" includes the following two basic assumptions: (1) the learning problem is the result of the inadequate functioning of one or more cognitive skills in the presence of intact intelligence (specificity); (2) there is a discrepancy between IQ and achievement. We have the impression that the learning disabilities of VCFS children show similarities with the learning disabilities of girls with Turner syndrome. Typically, visuospatial or spatialperceptual abilities or both are impaired in patients with Turner syndrome. ${ }^{21-24}$ However, it is clear that more studies are needed to define the type of learning disabilities in VCFS and answer questions regarding, for instance, visual and tactile attention of children with VCFS, differences between short term and long term memory, etc.

Very few data on the intelligence of children with VCFS have been reported so far. In a study by Golding-Kushner et al, ${ }^{4} 17$ children with VCFS received a psychometric intelligence assessment. The 4 year olds obtained mean IQs of 87 on the mainly verbal StanfordBinet and 84 on the Leiter International Performance test. The 8 year olds obtained a mean WISC-R verbal IQ of 76 and a mean performance IQ of 79. The 13 year olds obtained a verbal IQ of 79 and a mean performance IQ of 70 . Meaningful comparisons between the scores of the younger group and the two older groups could not be made, as the different tests may well assess different abilities.

A second topic of interest in the present study was the behaviour and the social compe- tence of children and adolescents with VCFS. In the group of young children aged between 2 and 3 years, somatic complaints ("constipation" and "eats poorly") and (social) withdrawal were often reported. The finding of constipation in many patients has not been reported before. This might suggest an abnormal motility of the large intestine. Several characteristics of VCFS are most likely related to an abnormal differentiation or migration of cranial neural crest cells. The caudal neural crest has a major role in Hirschsprung's disease, characterised by an abnormal motility of the large intestine. It cannot be not excluded that minor disturbances of the caudal neural crest also occur in VCFS, leading to poor colonic motility and constipation. Alternatively, the constipation might be related to the poor muscle tone found in most children with VCFS at a young age.

In the group of older normal/borderline intelligent children, three out of 12 children had a total $\mathrm{T}$ score within the clinical range. Clinical scores on the syndromes in individual patients were found on "Attention problems", "Social problems", "Thought problems", and "Withdrawn". The same behavioural profile but less pronounced was also found in patients with non-clinical scores. We found no differences between boys and girls, and this profile was already present at the age of 5 years.

In the group of mentally retarded children, two out of seven children had a total $T$ score within the clinical range. Clinical scores on the syndromes in individual patients were found on "Social problems" and on "Attention problems". We conclude therefore that children and adolescents with VCFS have social problems on one hand (most of the internalised type, withdrawal, social problems) and problems with attention/concentration already present at a young age on the other hand. So, children and adolescents with VCFS show extremes in their behaviour (withdrawn and shy on one hand, impulsive and disinhibited on the other hand). These findings are in accordance with the findings of Golding-Kushner et $a l,{ }^{4}$ who assessed behaviour and personality by a series of informal tests, interview, and parental history. The social withdrawal in children and adolescents with VCFS might result at least partly from their impaired ability to communicate with others. It might also be that neuropsychological deficits (visual-perceptual impairments, problems with new situations) contribute to their poorer social interaction skills. An important question is whether a pharyngoplasty and early speech therapy can improve speech and thus self-confidence.

In addition to social and attention problems, our data also point to higher scores on the anxiety/depression syndrome in the older children (11 years and older). Adolescent and adult patients with VCFS are at risk for developing psychiatric disorders including schizophrenia and depression. ${ }^{19}{ }^{25}$ The most common symptoms described in these reports are those associated with depression and anxiety disorders and include disturbed mood, severe vegetative symptoms, disturbed appetite, fatigue, and low 
self-esteem, as well as poor concentration and decision making ability. ${ }^{19}$ Therefore, the finding in this study of higher levels on the depression/anxiety scale in the older group is of interest, since this could be a first sign of developing psychopathology. Further prospective studies are needed to address this question.

To summarise, the present study showed that the incidence of mental retardation is much higher in the familial than in the de novo group. Intelligence is not correlated with the presence or absence of a heart defect. Significantly higher verbal IQs than lower performance IQs (probably related to deficits in visuospatialperceptual functioning) were found. Problems in social-emotional functioning and attention were found, and further studies are needed to assess the predictive value concerning their psychiatric status as adults. Longitudinal data and studies with control groups (children with a cleft palate or heart defect, children with learning disabilities, children with non-verbal learning disabilities) are needed to confirm these results and to show those deficits that are specific for VCFS. This will allow us to provide an accurate prognosis and appropriate intervention for VCFS children.

The authors wish to thank Dr Peter J Scambler for his kind gift of probe DO832, and all the families for their cooperation and support. We would like to express our gratitude to Lut Polleunis and Reinhilde Thoelen for their excellent technical assistance, and Rita Logist for helping in preparing the manuscript.

1 Shprintzen RJ, Goldberg RB, Lewin ML, et al. A new syndrome involving cleft palate, cardiac anomalies, typical facies and learning disabilities: velo-cardio-facial syndrome. Cleft Palate f 1978;15:56-62.

2 Scambler PJ, Kelly D, Lindsay E, et al. Velo-cardio-facial syndrome associated with chromosome 22 deletions syndrome associated with chromosome 22 deletions encoms

3 Motzkin B, Marion R, Goldberg R, et al. Variable phenotypes in velocardiofacial syndrome with chromosomal deletion $\mathcal{F}$ Pediatr 1993;123:406-10.

4 Golding-Kushner KJ, Weller G, Shprintzen RJ. Velo-cardiofacial syndrome: language and psychological profiles. $f$ Craniofac Genet 1985;51:259-66.

5 Devriendt K, Eyskens B, Swillen A, et al. The incidence of a deletion in chromosome 22q11 in sporadic and familial conotruncal heart disease. Eur $\mathcal{F}$ Pediatr 1996;155:721.
6 Wadey R, Daw S, Wickremasinghe A, et al. Isolation of a new marker and conserved sequences close to the DiGeorge syndrome marker HP500 (D22S134). F Med Genet 1993;30:818-22.

7 Van der Meulen BF, Smrkovsky M. Bayley ontwikkelingsschalen (BOS 2-30). Lisse: Swets \& Zeitlinger, 1983.

8 McCarthy D. Manual for the McCarthy scales of children's abilities. London: The Psychological Corporation, Harcourt Brace Jovanovich, 1972.

9 Van der Meulen BF, Smrkovsky M. McCarthy Ontwikkelingsschalen (MOS $21 / 2-81 / 2$ ). Lisse: Swets \& Zeitlinger, 1986.

10 Snijders JT, Snijders-Oomen M. Niet-verbale intelligentieschaal Revised (SON-R 2 1/2-7). Groningen: TjeenkWilling, 1985.

11 Stinissen J, Vander Steene G. WPPSI: Wechsler preschool and primary scale of intelligence. Handleiding bij de Vlaamse aanpassing. Lisse: Swets \& Zeitlinger, 1970.

12 Van Haasen PP, Vander Steene G, De Bruyn EEJ, et al. Wechsler intelligence scale for children-revised, Nederlandse uitgave. Lisse: Swets \& Zeitlinger, 1986.

13 Stinissen J, Willems PJ, Coetsier P, Hulsman WL. Handleiding bij de Nederlandse bewerking van de Wechsler adult intelligence scale (WAIS). Lisse: Swets \& Zeitlinger, 1970.

14 Terman LM, Merrill MA. Stanford-Binet intelligence scale manual for the third revision form L-M. Boston: Haughton Mufflin, 1973.

15 Verhulst FC, Koot JM, Akkerhuis GW, Veerman JW. Praktische handleiding voor de CBCL. Assen: Van Gorcum, 1990.

16 Achenbach TM. Integrative guide for the 1991 CBCL 4-18, YSR and TRF profiles. Burlington, VT: University of Vermont, Department of Psychiatry, 1991.

17 Lipson AH, Yuille D, Angel $M$, et al. Velocardiofacial (Shprintzen) syndrome: an important syndrome for the dysmorphologist to recognise. $\mathcal{F}$ Med Genet 1991;28:596604.

18 Shprintzen RJ, Goldberg RB, Young D, Walford L. The velo-cardio-facial syndrome: a clinical and genetic analysis. Pediatrics 1981;67:167-72.

19 Goldberg R, Motzkin B, Marion R, et al. Velo-cardio-facial syndrome: a review of 120 patients. Am $\mathcal{F}$ Med Genet 1993 45:313-19.

20 Mitnick RJ, Bello JA, Shprintzen RJ. Brain anomalies in velo-cardio-facial syndrome. Am f Med Genet 1994;54:100-

21 Waber DP. Neuropsychological aspects of Turner's syn drome. Dev Med Child Neurol 1979;21:58-70.

22 Pennington BF, Heaton RK, Karzmark P, et al. The neuropsychological phenotype in Turner syndrome. Cortex 1985;21:391-404.

23 Rovet J. The cognitive and neuropsychological characteristics of children with Turner syndrome. In: Berch D, Bender B, eds. Sex chromosome abnormalities in human behavior: psychological studies. Boulder, CO: Westview Pess, 1990:38-77.

24 Swillen A, Fryns JP, Kleckowska A, et al. Intelligence, behaviour and psychosocial development in Turne behaviour and psychosocial development in Turner adolescent girls (4-20 years). Genet Couns 1993;4:7-18.

25 Shprintzen RJ, Goldberg RB, Golding-Kushner KJ, Mario RW. Late-onset psychosis in the velo-cardio-facial syndrome. Am $\mathcal{F}$ Med Genet 1992;42:141-2. 